\title{
Radiographic assessment of pulmonary metastatic lesions in superficial cutaneous and mammary neoplasms in dogs"
}

S. L. Lekshmi ${ }^{\star 1}$, Sudheesh S Nair ${ }^{2}$, I. S. Sajitha ${ }^{3}$, Soumya Ramankutty ${ }^{2}$ (iD)

M. K. Narayanan ${ }^{4}$ and K. D. John Martin ${ }^{5}$ Department of Veterinary Surgery and Radiology, College of Veterinary and Animal Sciences, Mannuthy, 680651 Kerala Veterinary and Animal Sciences University, Kerala

Citation: Lekshmi, S.L., Sudheesh, S. N., Sajitha, I.S., Soumya, R., Narayanan, M.K. and John Martin, K.D. 2021. Radiographic assessment of pulmonary metastatic lesions in superficial cutaneous and mammary neoplasms in dogs. J. Vet. Anim. Sci. 52(4):393-398 DOI: https://doi.org/10.51966/jvas.2021.52.4.393-398

Received: 14.03.2021

Accepted: 16.04.2021

Published: 15.12.2021

\section{Abstract}

The present study was carried out to assess the pulmonary metastatic lesions in cases of canine superficial and mammary neoplasms presented to the University Veterinary Hospitals, Mannuthy and Kokkalai, Kerala Veterinary and Animal Sciences University during a twelve month period from February 2019 to February 2020. Twenty-four cases of neoplasms in dogs consisting of 12 cases of superficial neoplasms and 12 cases of mammary neoplasms were subjected to fine needle aspiration cytology (FNAC) for the confirmation of malignancy of neoplasm and threeview thoracic radiographs were taken to assess the pulmonary metastatic pattern. The results were correlated with the malignancy detected in histopathological analysis after excisional biopsy. The most commonly observed pulmonary metastatic lesions were pulmonary nodules followed by pulmonary micronodules, miliary nodules, and pulmonary mass. These lesions were more evident in malignant mammary neoplasms especially in tubulopapillary carcinoma, ductal carcinoma, and medullary mammary carcinoma with spatial arrangements more in the perihilar region followed by caudodorsal, midventral, and cranioventral area of lung parenchyma. In case of superficial neoplasms miliary patterns and pulmonary microndules were mostly detected as pulmonary metastatic pattern in soft tissue sarcoma, round cell tumour, and malignant fibrohistiocytoma.

Keywords: Superficial neoplasm, mammary neoplasm, pulmonary metastasis, computed thoracic radiography

Running title: Pulmonary metastatic lesions in cutaneous neoplasms in Dogs

"Part of M.V.Sc. thesis submitted by the first author to the Kerala Veterinary and Animal Sciences University, Pookode, Wayanad, Kerala

1. M.V.Sc. scholar and *Corresponding author email: lekshmi25krishna@gmail.com Ph.8281513730

2. Assistant Professor

3. Assistant Professor, Department of Veterinary Pathology

4. Professor

5. Professor and Head

Copyright: ( $\odot 2021$ Lekshmi et al. This is an open access article distributed under the terms of the Creative Commons Attribution 4.0 International License (http://creativecommons.org/licenses/by/4.0/), which permits unrestricted use, distribution, and reproduction in any medium, provided the original author and source are credited. 
Neoplasms are regarded as one of the most common diseases encountered in the pet population with reasons attributed to the drastic changes in the hormonal and environmental conditions. Canines are prone to develop neoplasms twice as frequently as humans (Rungsipipat et al., 2003). Skin neoplasms including that of subcutaneous tissue and adnexa are commonly observed in dogs followed by mammary neoplasms (Klopfleisch et al., 2010). The lung is the common site for metastasis in malignant mammary and superficial neoplasms and these metastatic changes may manifest as solitary or multiple pulmonary nodules in the parenchyma or as lymphangitic or endobronchial metastasis (Jung et al., 2004). Even though computerised tomography (CT) was found to be more sensitive than radiography for detection of pulmonary metastasis, radiography had a positive predictive value of 83 to 94 per cent in identifying thoracic metastatic lesions (Armbrust et al., 2012). Lateral thoracic radiographs alone can cause increased radio opacity which could lead to reduced contrast between pulmonary parenchyma and metastatic nodules located in these lobes. As a result, focal pulmonary consolidations or nodules may not be visible. Hence, the three- view thoracic radiographs (lateral and ventrodorsal/ dorsoventral views) are necessary for detecting early pulmonary metastasis for clinical staging of animals with cancer (Raditic and Bartges, 2014).

\section{Materials and methods}

Animals under study were divided in two groups of twelve animals each; group I with superficial cutaneous neoplasms, designated as $A_{1}$ to $A_{12}$ and group II with mammary neoplasms as $B_{1}$ to $B_{12}$. All cases were subjected to three- view thoracic radiographic evaluation (right lateral, left lateral and ventrodorsal views) using a $200 \mathrm{~mA}$ X-ray machine with computed radiography system. The shortest exposure time, highest $\mathrm{kVp}$ and low milliampere $\times$ second (mAs) (6-12.5 mAs) was used to minimize the effects of motion. Thoracic radiographs were interpreted for size, morphology, area of distribution of pulmonary metastatic lesions, and atypical pulmonary metastatic lesions. The pulmonary metastatic lesions were categorised as miliary nodules of $<2 \mathrm{~mm}$, pulmonary micronodules with $2-7 \mathrm{~mm}$, pulmonary nodule ranging from $7-30 \mathrm{~mm}$, and pulmonary mass with $>30 \mathrm{~mm}$ diameter. The distribution patterns of pulmonary metastases were recorded as single or multiple lesions in the perihilar, cranioventral, midventral and caudodorsal region of lung parenchyma as described by Mai et al. (2008). Atypical features such as tumour embolism (spray paint lesion), bronchial mineralization, calcification, cavitation signs, feeding vessel sign, haemorrhage and secondary pneumothorax (Seo et al., 2001) were also studied. The thoracic radiographic findings on pulmonary metastasis were correlated with the histopathology of the neoplasms.

\section{Results and discussion}

Specific pulmonary metastatic lesions and histopathological findings that were detected in the study are depicted in Table 1 and the radiographic features of metastasis including size, distribution of pulmonary metastases and atypical metastatic features are described in Table 2. The most commonly observed pulmonary metastatic lesions were pulmonary nodules followed by pulmonary micronodules, miliary nodules, and pulmonary mass in both groups. The most common pulmonary metastatic nodular pattern in superficial neoplasms were pulmonary micronodules and reticulonodular pattern (Fig. 1.A, 1.B, 2.A and 2.B, respectively) and that in mammary neoplasms were pulmonary nodules followed by pulmonary micronodules, miliary nodules, and pulmonary mass. Depending on the source and type of tumour, the pulmonary metastases could develop a wide range of radiographic appearance (Franquet et al., 2020). Lung consolidation might lead to the formation of pulmonary masses $(>30 \mathrm{~mm}$ size), which were observed in both superficial neoplasm (liposarcoma) (Fig. 3.A and 3.B) and mammary neoplasm (medullary mammary carcinoma) (Fig. 4.A and 4.B) in the present study. Similar unusual form of metastatic spread to the lung was characterized by lepidic growth of the tumor cells along the lining of the alveolar walls, resulting in a primary pulmonary adenocarcinoma like appearance (Franquet 
Table 1. Correlation between specific pulmonary metastatic lesions and histopathology of neoplasms

\begin{tabular}{|c|c|c|c|}
\hline Group & $\begin{array}{c}\text { Animal } \\
\text { Number }\end{array}$ & $\begin{array}{c}\text { Specific pulmonary metastatic lesions } \\
\text { (Thoracic radiograph) }\end{array}$ & $\begin{array}{l}\text { Histopathology of } \\
\text { Primary Tumour }\end{array}$ \\
\hline \multirow{12}{*}{ 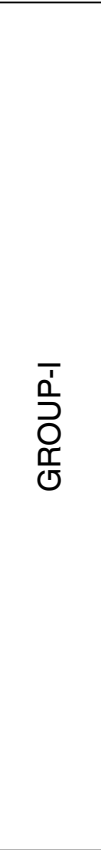 } & $A_{1}$ & No metastatic lesion, pneumothorax & Sebaceous adenoma \\
\hline & $A_{2}$ & $\begin{array}{l}\text { No metastatic lesion, pleural effusion, sternal } \\
\text { lymphadenopathy }\end{array}$ & Fibroma \\
\hline & $\mathrm{A}_{3}$ & $\begin{array}{l}\text { Pulmonary micronodule and mixed } \\
\text { disseminated alveolar interstitial pattern }\end{array}$ & Plasma cell tumour \\
\hline & $\mathrm{A}_{4}$ & $\begin{array}{l}\text { Reticulonodular and mixed disseminated } \\
\text { alveolar interstitial pattern }\end{array}$ & Trichoblastoma (solid) \\
\hline & $A_{5}$ & $\begin{array}{l}\text { Reticulonodular and mixed disseminated } \\
\text { alveolar interstitial pattern }\end{array}$ & Apocrine adenoma \\
\hline & $A_{6}$ & Pulmonary micronodules, pulmonary nodules & $\begin{array}{l}\text { Sebaceous } \\
\text { adenocarcinoma }\end{array}$ \\
\hline & $A_{7}$ & $\begin{array}{l}\text { Pulmonary micronodules pulmonary nodules, } \\
\text { pulmonary mass, sternal lymphadenopathy }\end{array}$ & Liposarcoma \\
\hline & $A_{8}$ & $\begin{array}{l}\text { Pulmonary micronodules and reticulonodular } \\
\text { pattern, sternal lymphadenopathy }\end{array}$ & Squamous cell carcinoma \\
\hline & $A_{9}$ & $\begin{array}{l}\text { Pulmonary micronodules, pulmonary nodules, } \\
\text { pulmonary mass and reticulonodular pattern }\end{array}$ & Malignant fibrohistocytoma \\
\hline & $A_{10}$ & $\begin{array}{l}\text { Miliary nodules, pulmonary micronodules and } \\
\text { reticulonodular pattern }\end{array}$ & Squamous cell carcinoma \\
\hline & $A_{11}$ & $\begin{array}{l}\text { Pulmonary micronodules pulmonary nodules, } \\
\text { sternal lymphadenopathy }\end{array}$ & Squamous cell carcinoma \\
\hline & $A_{12}$ & No metastasis & Hepatoid gland carcinoma \\
\hline \multirow{12}{*}{ 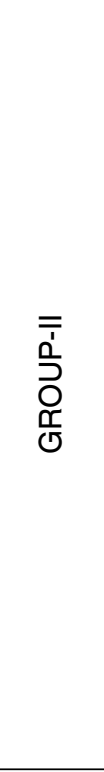 } & $\mathrm{B}_{1}$ & $\begin{array}{l}\text { Pulmonary nodule and pulmonary mass, pleural } \\
\text { effusion, sternal lymphadenopathy }\end{array}$ & Ductal carcinoma \\
\hline & $\mathrm{B}_{2}$ & $\begin{array}{l}\text { Pulmonary micronodules, Pulmonary nodules } \\
\text { and reticulonodular }\end{array}$ & Tubulopapillary carcinoma \\
\hline & $\mathrm{B}_{3}$ & $\begin{array}{l}\text { Miliary nodules, pulmonary micronodules and } \\
\text { reticulonodular pattern, pleural effusion }\end{array}$ & Ductal carcinoma \\
\hline & $\mathrm{B}_{4}$ & Pulmonary nodule & Tubulopapillary carcinoma \\
\hline & $\mathrm{B}_{5}$ & $\begin{array}{l}\text { Pulmonary micronodule and reticulonodular } \\
\text { pattern }\end{array}$ & Ductal carcinoma \\
\hline & $\mathrm{B}_{6}$ & $\begin{array}{l}\text { Miliary nodules, pulmonary micronodules and } \\
\text { mixed disseminated alveolar interstitial pattern, } \\
\text { pleural effusion, pneumothorax }\end{array}$ & Solid carcinoma \\
\hline & $\mathrm{B}_{7}$ & Pulmonary nodule & Spindle cell sarcoma \\
\hline & $\mathrm{B}_{8}$ & Pulmonary nodule & Ductal carcinoma \\
\hline & $\mathrm{B}_{9}$ & No metastasis, pneumothorax & Fibroadenoma \\
\hline & $\mathrm{B}_{10}$ & Mixed disseminated alveolar interstitial pattern & Ductal carcinoma \\
\hline & $\mathrm{B}_{11}$ & $\begin{array}{l}\text { Pulmonary mass, pleural effusion, sternal } \\
\text { lymphadenopathy }\end{array}$ & $\begin{array}{l}\text { Medullary mammary } \\
\text { carcinoma }\end{array}$ \\
\hline & $\mathrm{B}_{12}$ & Pulmonary nodule & Ductal cell carcinoma \\
\hline
\end{tabular}

et al., 2020). In the present study, most of the metastatic lesions were located in the perihilar region followed by the caudodorsal, midventral and cranioventral areas. The maximum number of metastatic lesions were observed uniformly all over the lung as reported by Gowthami (2017). Other metastatic patterns such as interstitial disseminated reticulonodular pattern and mixed disseminated alveolar interstitial pattern observed in right lateral view were 33.33 per cent and 16.67 per cent respectively in Group I and 25 per-cent and 16.67 per cent in Group II. The atypical metastatic lesions such as calcification, secondary pneumothorax and cavitation signs were also observed during advanced stages of metastasis (ductal cell 


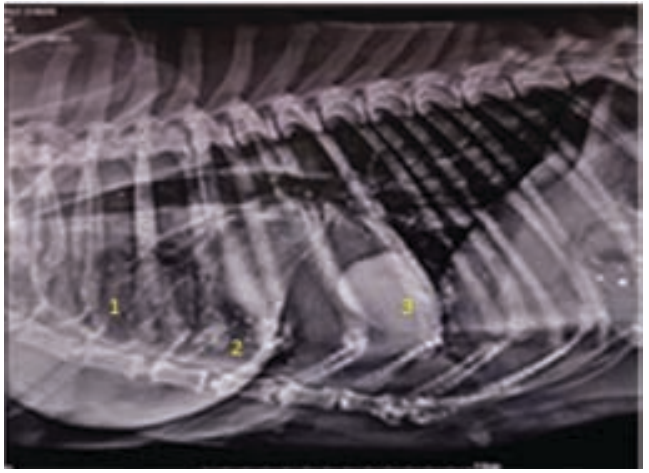

Fig. 1. A. Skiagram of throrax of a dog showing Pulmonary miliary nodules (1), pulmonary micronodules(2) at cranioventral region and pulmonary mass (3) at caudoventral region of lung parenchyma in right lateral view (Case $\mathrm{A}_{9}$ diagnosed as fibrohistiocytoma)

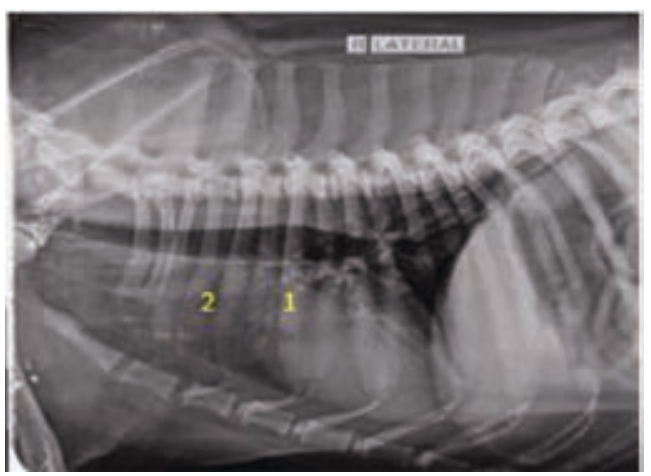

Fig. 2. A. Skiagram of thorax of a dog showing pulmonary micronodules (1) and mixed disseminated alveolar interstitial pattern (2) in the right lateral view (Case $\mathrm{A}_{3}$ - diagnosed as plasma cell tumour)

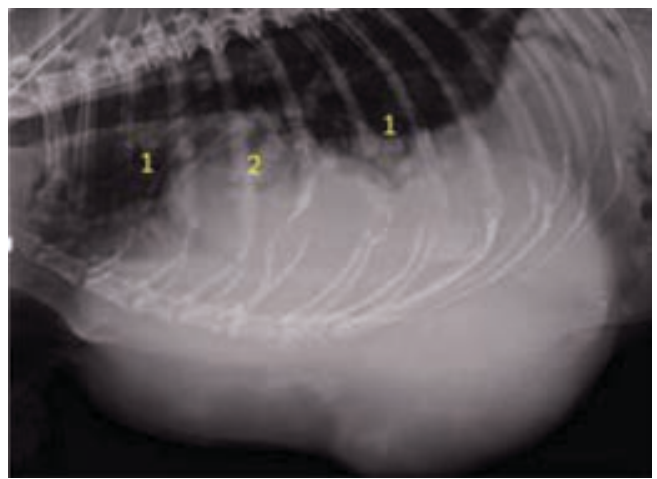

Fig. 3. A: Skiagram of thorax of dog showing pulmonary nodules (1) (Size $-6.1-28.32 \mathrm{~mm}$ ) in the cranioventral, perihilar, caudo ventral and midventral areas of lung parenchyma and probable feeding vessel sign (2) in the right lateral view ( Case $A_{7}$ diagnosed as liposarcoma)

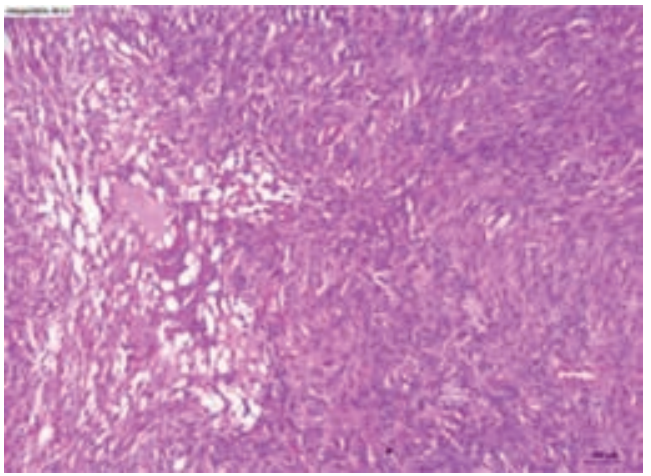

Fig 1. B. Malignant fibrohistiocytoma (Case $\mathrm{A}_{9}$ ) Presence of numerous spindle cells and mononuclear histiocytoid cells $(H \& E \times 200)$

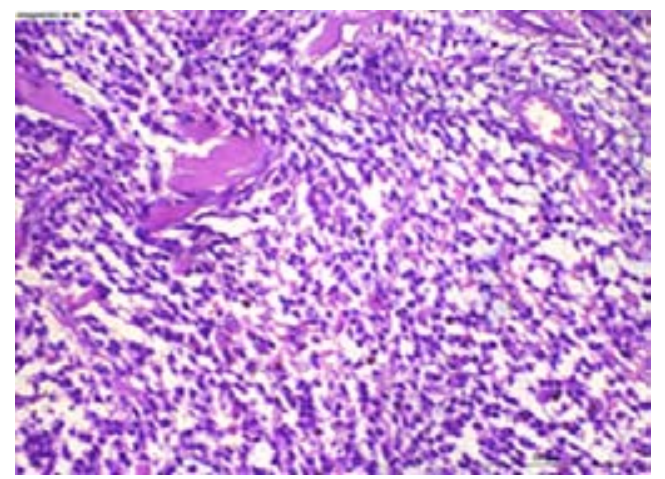

Fig 2. B. Plasma cell tumour (Case $\left.A_{3}\right)$

Presence of sheets of round cells with hyperchromatic and eccentric nuclei (H\&E $\times 200$ )

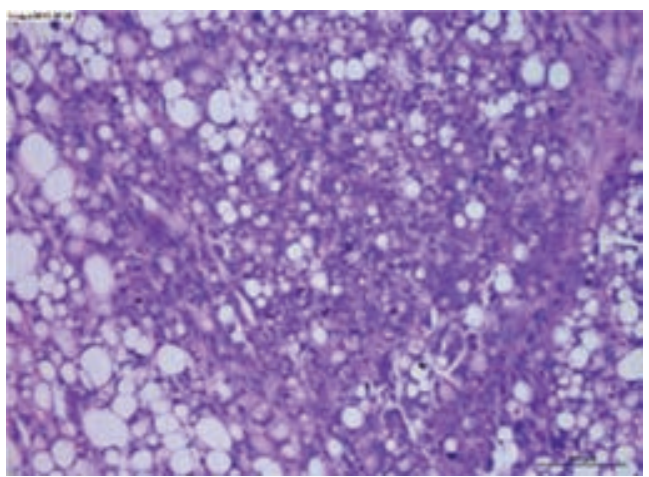

Fig. 3. B: Liposarcoma (Case $A_{7}$ )

Presence of anaplastic and pleomorphic cells of highly variable morphology, large bizzare multinucleated cells and intracytoplasmic fat vacuoles $(H \& E \times 200)$ 


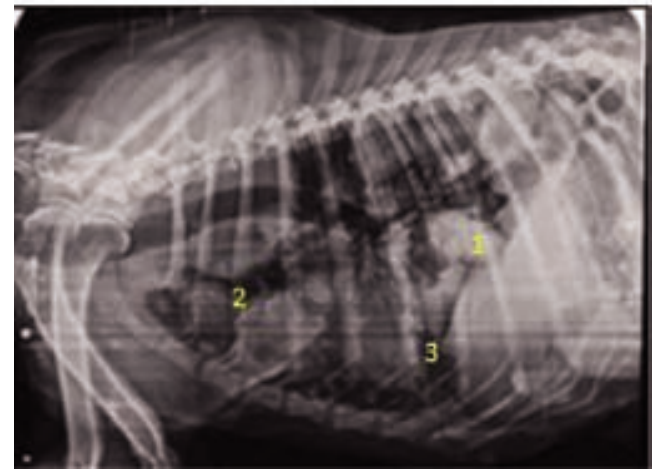

Fig. 4. A: Skiagram of thorax of a dog showing diffused pulmonary masses (Size $>30 \mathrm{~mm}$ ) (1), probable cavitation signs (2) and secondary pneumothorax (3) in right lateral view (Case $B_{11}$ diagnosed as medullary mammary carcinoma)

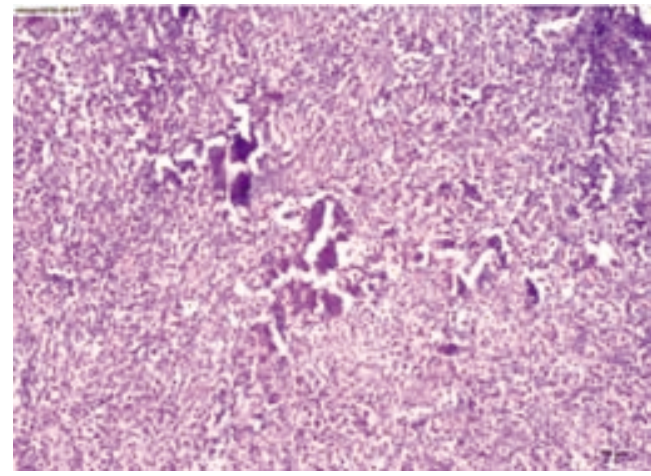

Fig. 4. B: Medullary mammary carcinoma $\left(\right.$ Case $\left.B_{11}\right)$

Carcinomatous growth composed of sheets and groups of large pleomorphic, polyhydral or oval cells having larger nuclei. Stroma shows hyalinisation and haemorrhage (H\&Ex200)

Table 2. Radiographic assessment of pulmonary metastatic lesions in dogs with superficial (Group - I) and mammary (Group-II) neoplasms

\begin{tabular}{|c|c|c|c|c|c|c|c|}
\hline SI. No & Type of lesion & \multicolumn{3}{|c|}{ Group I } & \multicolumn{3}{|c|}{ Group II } \\
\hline \multicolumn{8}{|c|}{ Based on Size (Number of animals) } \\
\hline & & $\mathbf{R L}$ & LL & VD & RL & LL & VD \\
\hline 1 & Miliary nodules $<2 \mathrm{~mm}$ & 3 & 3 & 1 & 2 & 2 & 0 \\
\hline 2 & Pulmonary micronodule (2-7 mm) & 7 & 8 & 3 & 4 & 4 & 1 \\
\hline 3 & Pulmonary nodule $(7-30 \mathrm{~mm})$ & 2 & 4 & 2 & 6 & 4 & 3 \\
\hline 4 & Pulmonary mass (>30mm) & 1 & 1 & 1 & 2 & 1 & 1 \\
\hline \multicolumn{8}{|c|}{ Based on distribution pattern (Number of animals) } \\
\hline 1 & Interstitial disseminated reticulonodular pattern & 4 & 3 & 1 & 3 & 3 & 1 \\
\hline 2 & Mixed disseminated alveolar interstitial pattern & 2 & 1 & 0 & 2 & 2 & 1 \\
\hline \multicolumn{8}{|c|}{ Atypical features (Number of animals) } \\
\hline 1 & Tumour embolism & - & - & $\mathrm{x}$ & - & - & $\mathrm{X}$ \\
\hline 2 & Calcification & 2 & 2 & $\mathrm{X}$ & 3 & 3 & $\mathrm{x}$ \\
\hline 3 & Cavitation signs & 2 & 1 & $\mathrm{x}$ & 2 & 2 & $\mathrm{x}$ \\
\hline 4 & Secondary pneumothorax & 1 & 2 & $\mathrm{x}$ & 3 & 3 & $\mathrm{x}$ \\
\hline 5 & Feeding vessel sign & - & - & $\mathrm{x}$ & 2 & 2 & $\mathrm{x}$ \\
\hline
\end{tabular}

$\mathrm{RL}$ - Indicates right lateral view

LL - Indicates left lateral view

VD - Indicates ventrodorsal view

$X$ - Indicate the lesions that were not identified on that view

carcinoma, medullary mammary carcinoma and liposarcoma). Pneumothorax was observed in two cases of mammary neoplasms $\left(B_{6}\right.$ and $\left.B_{9}\right)$ and one superficial neoplasm $\left(A_{1}\right)$. Spontaneous pneumothorax might be the initial sign of pulmonary metastasis and Seo et al. (2001) proposed mechanisms as the formation of bronchopleural fistula due to tumour necrosis. Weerakkody and Niknejad (2019) reported a "feeding vessel sign", which consisted of a distinct vessel leading directly to a nodule or a mass, which was suspected in two cases of advanced pulmonary metastasis (ductal cell carcinoma and medullary mammary carcinoma).

\section{Conclusion}

Thoracic radiography was found to be reliable, cost and time effective diagnostic procedure for identification of initial or advanced stages of pulmonary metastasis 
associated with superficial and mammary neoplasms. Even though thoracic radiography is the primary diagnostic choice for pulmonary metastasis, there are limitations for using this as confirmatory diagnosis; most of the soft tissue nodules of diameter less than $0.5 \mathrm{~mm}$ could not be done by thoracic radiography. Diagnosis of feeding vessel signs, cavitation, tumour embolism and haemorrhage around the nodule needed further advanced techniques such as CT or MRI.

\section{Acknowledgement}

The authors wish to thank the Kerala Veterinary and Animal Sciences University for providing all the necessary facilities to conduct the research work.

\section{Conflict of interest}

The authors declare that they have no conflict of interest.

\section{References}

Armbrust, L.J., Biller, D.S., Bamford, A., Chun, R., Garrett, L.D. and Sanderson, M.W. 2012. Comparison of three-view thoracic radiography and computed tomography for detection of pulmonary nodules in dogs with neoplasia. J. Am. Vet. Med. Assoc. 240: 1088-1094.

Franquet, T., Rosado-de-Christenson, M.L., Marchiori, E., Abbott, G.F., MartínezJiménez, S. and López, L. 2020. Uncommon thoracic manifestations from extrapulmonary tumors: Computed tomography evaluation-Pictorial review. Respir. Med. 20: 105-986.

Gowthami, N.G.V. 2017. Computerized radiographic studies of thorax in geriatric dogs. M.V.Sc. thesis, Sri Venkateswara Veterinary University, Thirupati, 148p.
Jung, J.I., Kim, H.H., Park, S.H., Song, S.W., Chung, M.H., Kim, H.S., Kim, K.J., Ahn, M.I., Seo, S.B. and Hahn, S.T. 2004. Thoracic manifestations of breast cancer and its therapy. Radiographics. 24: 12691285.

Klopfleisch, R., Klose, P., Weise, C., Bondzio, A., Multhaup, G., Einspanier, R. and Gruber, A.D.2010. Proteome of metastatic canine mammary carcinomas: similarities to and differences from human breast cancer. J. Proteome Res. 9: 6380-6391.

Mai,W., Q'Brien, R., Scrivani, P., Porat-Mosenco, V., Tobin, E., Seiler, G., McConnell, F., Schwarz, T. and Zwingenberger, A. 2008. The lung parenchyma In: Schwarz, T. and Johnson, V. (eds.), BSAVA Manual of canine and feline thoracic imaging. BSVA, Gloucester, pp. 240-320.

Seo, J.B., Im, J.G., Goo, J.M., Chung, M.J. and Kim, M.Y. 2001. Atypical pulmonary metastases: spectrum of radiologic findings. Radiographics. 21: 403-417.

Rungsipipat, A., Suryasootcharee, B., Ousawaphlangchi, L., Sailasuta, A., Thanawongnuwech, R., Teankum, K. and Lek, O. 2003. Neoplasms in dogs in Bangkok. Tailand J. Vet. Med. 33: 59-66.

Weerakkody. 2020. Pulmonary Metastasis. Radiopaedia. Available: https:// radiopaedia.org/articles/pulmonarymetastasis. [On Dec 2020].

Weerakkody and Niknejad. 2020. Pulmonary Metastasis. Radiopaedia. Available: https://radiopaedia.org/articles/ pulmonary-metastases. [On Oct 2020].

Woodring, J.H. 1990. Pitfalls in the radiologic diagnosis of lung cancer. AJR. Am. J. Roentgenol. 154: 1165-1175. 